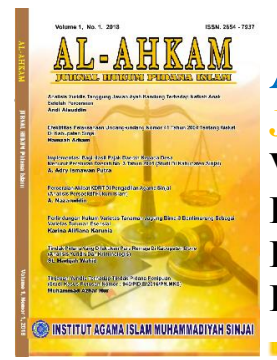

\title{
HUKUM DAN IKLAN PENGOBATAN TRADISONAL DI KOTA MAKASSAR
}

\author{
Mulawarni ${ }^{1}$, Hamzah Arhan ${ }^{2}$, Nazaruddin ${ }^{3}$ \\ ${ }^{1}$ Universitas Hasanuddint Jl. Perintis Kemerdekaan KM.10, Makassar \\ ${ }^{2}$ Institut Agama Islam Muhammadiyah Sinjai, Jl.Sultan Hasanuddin No.20, Kabupaten Sinjai \\ ${ }^{3}$ Institut Agama Islam Muhammadiyah Sinjai, Jl.Sultan Hasanuddin No.20, Kabupaten Sinjai \\ E-mail: hamzaharhan68@gmail.com,Tlp:+6285239706086
}

\begin{abstract}
Abstrak
Pengobatan tradisional merupakan alternatif pilhan konsumen yang saat ini sedang berkembang, dimana perkembangan tersebut dapat dilihat dengan banyaknya iklan pengobatan tradisional yang dengan mudah ditemukan di beberapa media, namun banyaknya iklan tidak sejalan dengan aturan yang berlaku karena beberapa iklan yang dibuat ternyata melanggar aturan.Tujuan dari penelitian ini adalah untuk mengetahui pelaksanaan Peraturan Menteri Kesehatan Nomor 1787 dan Keputusan Menteri Kesehatan Nomor 1067 dalam peredaran iklan pengobatan tradisional di Kota Makassar dan pengawasan Dinas Kesehatan terhadap pelaksanaan Peraturan Menteri Kesehatan Nomor 1787 dan Keputusan Menteri Kesehatan Nomor 1067 dalam peredaran iklan pengobatan tradisional di Kota Makassar. Penelitian ini menggunakan jenis penelitian yuridis empiris. Sampel ditetapkan secara purposive. Data yang diteliti meliputi data primer, yaitu data yang diperoleh melalui wawancara langsung dengan narasumber dan bahan sekunder dari literature yang terkait. Data dianalisis secara deskriptif kualitatif. Hasil penelitian menunjukkan bahwa pelaksanaan Permenkes Nomor 1787 Tahun 2010 dan Kepmenkes Nomor 1076 Tahun 2003 dalam peredaran iklan pengobatan tradisional di Kota Makassar tidak berjalan efektif. Masih banyak ditemukan pelanggaran yang dilakukan oleh pengobat tradisional dan media pengiklan dalam menayangkan iklan. ketidak efektifan aturan tersebut disebabkan oleh beberapa kendala yaitu; terlambatnya sosialisasi yang dilakukan oleh Dinas Kesehatan, sosialisasi yang dilakukan tidak secara menyeluruh kepada pihak-pihak yang terkait.Pengawasan yang dilakukan oleh dinas Kesehatan Kota Makassar terhadap iklan pengobatan tradisional dilakukan dengan cara membentuk tim khusus untuk pengawasan yang lebih ketat terhadap pengobat tradisional. Pemberian sanksi andministratif dinilai tidak memberikan efek jera. Dinas Kesehatan Kota Makassar bekerja sama dengan Komisi Penyiaran Indonesia Daerah untuk melakukan pengawasan terhadap iklan pengobatan tradisional yang ada dimedia televisi.
\end{abstract}

Kata Kunci: Pelanggaran, Pengawasan, Iklan, Pengobatan Tradisional.

\begin{abstract}
Traditional medicine is an alternative choice for consumers that are currently developing, where this development can be seen by the number of traditional medicine advertisements that are easily found in several media, but the number of advertisements is not in line with the applicable regulations because some of the advertisements that are made actually violate the rules. This research is to determine the implementation of the Minister of Health Regulation No. 1787 and the Decree of the Minister of Health No. 1067 in the distribution of traditional medicine advertisements in Makassar City and the supervision of the Health Office on the implementation of the Minister of Health
\end{abstract}




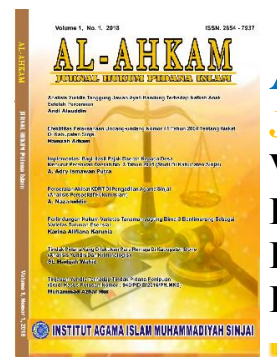

Al-Ahkam

Jurnal Hukum Pidana Islam

Volume 2, No. 2, 2020

ISSN (print) : 2654-7937

ISSN (online) : 2715-0313

Homepage :http://journal.iaimsinjai.ac.id/index.php/al-ahkam/index

Regulation No. 1787 and the Minister of Health Decree No. 1067 in the distribution of traditional medicine advertisements in Makassar City. . This research uses empirical juridical research. The sample was determined purposively. The data studied included primary data, namely data obtained through direct interviews with sources and secondary materials from related literature. Data were analyzed descriptively qualitatively. The results showed that the implementation of Permenkes No. 1787/2010 and Kepmenkes No. 1076/2003 in the distribution of traditional medicine advertisements in Makassar City was not effective. There are still many violations committed by traditional healers and advertisers in serving advertisements. the ineffectiveness of these rules is caused by several obstacles, namely; the late socialization carried out by the Health Office, the dissemination carried out not thoroughly to the parties concerned. The supervision carried out by the Makassar City Health Office on traditional medicine advertisements was carried out by forming a special team for tighter supervision of traditional healers. Administrative sanctions are considered not to provide a deterrent effect. The Makassar City Health Office cooperates with the Regional Indonesian Broadcasting Commission to supervise advertisements for traditional medicine on television.

Keywords: Violation, Surveillance, Advertising, Traditional Medicine.

\section{Pendahuluan}

Iklan adalah segala bentuk promosi yang ditujukan untuk memperbesar penjualan barang dan jasa dari pemberi pesan kepada masyarakat dengan mempergunakan media yang dibayar berdasarkan tarif tertentu (Harianto, 2010). Iklan merupakan salah satu bentuk spesialisasi untuk mempertemukan satu pihak yang menawarkan sesuatu dengan pihak lain yang membutuhkannya (Simatupang, 2004).

Iklan sebagai sarana pemasaran dan sarana penerangan, yang memegang peranan penting dalam pembangunan bangsa Indonesia. Sehubungan dengan itu ,maka (1) Iklan harus jujur, bertanggungjawab, dan tidak bertentangan dengan hukum yang berlaku; (2)Iklan tidak boleh menyinggung perasaan dan/atau merendahkan martabat, agama, tata susila, adat, budaya, suku dan golongan; (2) Iklan harus dijiwai oleh asas persaingan yang sehat (Wijaya \& Yani, 2008).

Semakin besarnya pengaruh iklan terhadap perilaku masyarakat atau konsumen, membuat para pelaku usaha semakin kreatif dalam menyugukan iklan produk mereka. Iklan masa kini tidak berputar di lingkaran ekonomi semata, iklan sudah bertransformasi menjadi sumber inspirasi gaya hidup, tred, kebiasaan, serta cara pandang bagi masyarakat. Ketika iklan menyapa, dikemas dengan tampilan menarik, sebagian masyarakat lebih ingat dengan bonus-bonus menarik yang ditawaran iklan, hadiah-hadiah yang memanjakan atau seperangkat alat bujuk rayunya. Sehingga, masyarakat lupa dengan apa yang sebenarnya mereka butuhkan (Myres, 2012).

Segala macam keunggulan dari iklan yang ditampilkan sudah seharusnya sesuai dengan aturan yang berlaku, terutama dalam hal pemberian informasi yang benar kepada konsumen. Hal ini diatur dalam Pasal 4 Undang- Undang Nomor 8 Tahun 1999 tentang Perlindungan Konsumen (selanjutnya akan disingkat UUPK ) yaitu konsumen berhak memperoleh informasi yang benar, jelas dan jujur. Hak atas informasi yang benar dimaksudkan agar konsumen dapat memperoleh gambaran yang benar tentang suatu produk (Miru \& Yodo, 2008).

Iklan yang merupakan sarana untuk memperkenalkan suatu produk atau jasa kepada masyarakat luas atau konsumen juga di pergunakan di bidang kesehatan untuk 


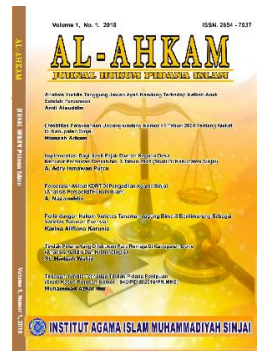

Al-Ahkam

Jurnall Hukum Pidana Islam

Volume 2, No. 2, 2020

ISSN (print) : 2654-7937

ISSN (online) : 2715-0313

Homepage :http://journal.iaimsinjai.ac.id/index.php/al-ahkam/index

memperkenalkan produk ataupun jasa kesehatan (Notoatmodjo, 2010). Sebagai contoh promosi dibidang kesehatan adalah maraknya iklan pengobatan tradisional atau pengobatan herbal yang genjar di promosikan melalui iklan media televisi, koran, dan brosur yang disebaran.

Pentingnya sebuah kesehatan membuat beberapa orang terkadang tidak berfikir panjang, mencoba segala macam kemungkinan yang bias dilakukan untuk menyembuhkan penyakit. Hal ini merupakan peluang yang sangat baik bagi pengobat tradisional untuk mempromosikan jasa pelayanan kesehatan dan obat herbal mereka. Tujuan dari penelitian ini adalah mengetahui pelaksanaan Peraturan Menteri Kesehatan Nomor 1787 dan Keputusan Menteri Kesehatan Nomor 1067 dalam peredaran iklan pengobatan tradisional di Kota Makassar dan mengetahui pengawasan Dinas Kesehatan terhadap pelaksanaan Peraturan Menteri Kesehatan Nomor 1787 dan Keputusan Menteri Kesehatan Nomor 1067 dalam peredaran iklan pengobatan tradisional di Kota Makassar.

\section{Metode}

\subsection{Lokasi Penelitian dan Rancangan Penelitian}

Penelitian tentang "Iklan pengobatan tradisional" dilakukan di Kota Makassar, yaitu Kantor Dinas Kesehatan Kota Makassar, Kantor Komisi Penyiaran Indonesia Daerah (KPID) Sulawesi selatan dan konsumen pengguna jasa pengobatan tradisional. Penelitian ini didesain dengan metode deskriptif untuk memperoleh gambaran sejauh mana pelanggaran yang dilakukan dalam peredaran iklan pengobatan tradisional.

\subsection{Populasi dan Sampel}

Adapun populasi dari penelitian ini yaitu seluruh pihak yang terkait dalam peredaran dan pengawasan iklan pengobatan tradisional. pihak-pihak yang terkait di dalam hal ini, antara lain meliputi konsumen pengguna jasa pengobatan tradisional,Dinas Kesehatan Kota Makassar, dan KPID Sulawesi Selatan.

Adapun pengambilan sampel dalam penelitian ini yaitu 3 (tiga) orang SDM Dinas Kesehatan Kota Makassar, 2 (dua) orang SDM Kantor Komisi Penyiaran Indonesia Daerah Sulawesi Selatan dan 10 (sepuluh) orang konsumen pengguna jasa pengobatan tradisional.

\subsection{Pengumpulan Data}

Teknik pengumpulan data primer dan sekunder yang penulis gunakan antara lain studi kepustakaan/dokumentasi, yaitu menelaah bahan-bahan tertulis berupa buku-buku, dokumen resmi peraturan perundang-undangan, serta sumber tertulis lain yang berkaitan dengan masalah yang diteliti (Marzuki \& Peter, 2011); serta wawancara yaitu usaha pengumpulan data yang dilakukan dengan cara melakukan tanya jawab langsung berkaitan dengan penelitian. Wawancara dalam pengumpulan data dilakukan terhadap narasumber dari masing-masing lokasi penelitian (Amiruddin, 2004).

\subsection{Analisis Data}

Data-data yang diperoleh kemudian diolah dengan menggunakan metode deskriptif kulaitatif untuk memperoleh suatu kesimpulan dari masalah yang diteliti.

\section{Hasil dan Pembahasan}

\subsection{Hasil}

Perkembangan pengobatan tradisonal semakin hari semakin pesat. Di Kota Makassar sendiri terdaftar kurang lebih 80 klinik pengobatan tradisional. Banyaknya klinik pengobatan tradisional, membuat mereka bersaing untuk memperoleh perhatian dan kepercayaan konsumen. Untuk memperkenalkan jasa pengobatan mereka, iklan 


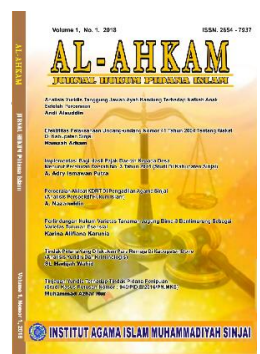

Al-Ahkam

Jurnall Hukum Pidana Islam

Volume 2, No. 2, 2020

ISSN (print) : 2654-7937

ISSN (online) : 2715-0313

Homepage :http://journal.iaimsinjai.ac.id/index.php/al-ahkam/index

merupakan salah satu cara yang paling efektif. Iklan pengobatan tradisional dapat dengan mudah dijumpai dalam keseharian kita baik ditelivisi, Koran maupun melalui brosur.

Berdasarkan hasil penelitian dilapangan menunjukkan bahwa dari 10 (sepuluh) konsumen pengguna jasa 20\% mengatakan bahwa iklan yang ditayangakan sesuai dengan fakta dilapangan, $40 \%$ mengatakan tidak sesuai, dan $40 \%$ mengatakan belum tau. Berdasarkan data yang diperoleh dari Komisi Penyiaran Indonesia (KPID) Sulewesi Selatan menunjukkan bahwa hingga tahun 2015 masih ditemukan pelanggaran iklan pengobatan tradisional yang ditayangkan dibeberapa stasiun televisi lokal di Kota Makassar.

Berdasarkan UUPK Pasal 9 bahwa pelaku usaha dilarang menawarkan, mempromosikan, mengiklankan suatu barang dan/atau jasa secara tidak benar dan/atau seolah-olah (j) menggunakan kata-kata yang berlebihan, seperti aman, tidak berbahaya, tidak mengandung risiko, atau efek samping tanpa keterangan yang jelas;(k) menawarkan sesuatu yang mengandung janji yang belum pasti. Lebih khusu mengenai pengobatan trdisional diatur dalam Pasal 13 ayat (2) menyatakan bahwa pelaku usaha dilarang menawarkan, mempromosikan atau mengiklankan obat, obat tradisonal, suplemen makanan, alat kesehatan, dan jasa pelayanan kesehatan dengan cara menjanjikan pemberian hadiah berupa barang dan atau jasa.

Terkait dengan iklan jasa pengobatan tradisional juga diatur dalam Peraturan Menteri Kesehatan Nomor 1787 tahun 2010 tentang Iklan dan Publikasi Layanan Kesehatan Pasal 5 yang menyatakan bahwa iklan dan/atau publikasi layanan kesehatan tidak diperbolehkan apabila bersifat (b) memberikan informasi atau pernyataan yang tidak benar,palsu, bersifat menipu, dan menyesatkan;(e) memuji diri secara berlebihan, termasuk pernyataan yang bersifat superlative dan menyiratkan kata"satu-satunya" atau bermakna sama mengenai keunggulan, keunikan atau kecanggihan sehingga cenderung bersifat merugikan;(f) mempublikasikan metode, obat, alat dan/atau teknologi pelayan baru atau non konvensional yang belum diterima oleh masyarakat kedokteran dan/atau kesehatan karena manfaat dan kemanannya sesuai ketentuan masing-masing masih diragukan atau belum terbukti;(m) mengiklankan promosi penjualan dalam bentuk apapun termasuk pemberian potongan harga (diskon), imbalan atas pelayanan kesehatan, dan/atau menggunakan metode penjualan multilevel marketing; (n) memberikan testimony dalam bentuk iklan dan publikasi dimedia massa.

Selain itu, iklan pengobatan tradisional juga diatur dalam Keputusan Mentri Kesehatan Nomor 1067 tentang Pelaksanaan Pengobatan tradisional dalam Pasal 23 yaitu (1) Pengobat tradisional dilarang mempromosikan diri secara berlebihan dan memberikan informasi yang menyesatkan; (2) informasi menyesatkan sebagaimana dimaksud ayat (1) yaitu;a).Penggunaan gelar tanpa melalui jenjang pendidikan dari sarana pendidikan terakreditasi,b).menginformasikan bahwa pengobatan tersebut dapat menyembuhkan semua penyakit,c). Menginformasikan telah memiliki surat terdaftar/surat izin sebagai pengobat tradisional yang pada kenyataannya tidak dimilikinya.

\subsection{Pembahasan}

Penelitian ini menunjukkan bahwa iklan pengobatan tradisional yang beredar di masyarakat telah melanggar beberapa aturan baik yang terdapat dalam Peraturan Menteri Kesehatan tentang Iklan dan Publikasi Kesehatan, Keputusan Menteri Kesehatan tentang Pelaksanaan Pengobatan Tradisional, maupun berdasarkan UUPK. Pelanggaran yang dilakukan terutama dalam hal pemberian informasi yang dianggap menyesatkan dan berlebih-lebihan, penggunaan testimoni dan pemberian potongan harga.

Pemberian informasi yang benar yang terdapat dalam Pasal 9 UUPK terkait dengan representasi, dimana pelaku usaha wajib memberikan representasi yang benar atas 


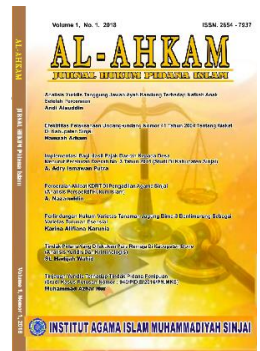

Al-Ahkam

Jurnall Hukum Pidana Islam

Volume 2, No. 2, 2020

ISSN (print) : 2654-7937

ISSN (online) : 2715-0313

Homepage :http://journal.iaimsinjai.ac.id/index.php/al-ahkam/index

barang dan/atau jasa yang diperdagangkannya. Hal ini penting karena sebagaimana diketahui bahwa salah satu penyebab terjadinya kerugian konsumen adalah misrepresentasi terhadap barang dan/atau jasa tertentu. Kerugian yang dialami olek konsumen juga kebanyakan karena tergiur oleh iklan-iklan atau brosur-brosur yang ternyata tidak benar (Miru \& Yodo, 2008).

Pelarangan penggunaan testimoni dalam sebuah iklan pengobatan tradisonal karena dikhawatirkan orang yang mengaku pasien dan memberikan testimoninya dalam iklan merupakan sebuah rekayasa belaka hanya untuk meyakinkan konsumen. Reaksi yang berbeda dari setiap pasien setelah melakukan pengobatan juga menjadi alasan kenapa testimoni tidak diperbolehkan. Pasien mungkin saja memiliki penyakit yang sama tetapi tidak semua pasien cocok dengan obat maupun cara pengobatan yang sama dengan pasien lainnya. Seperti diatur dalam Permenkes Nomot 1787 Pasal 5 huruf (n) yaitu dilarang member testimoni dalam bentuk iklan atau publikasi di media massa. Sedangkan pelarangan pemberian potongan harga ataupun pemberian berupa hadiah sebagaimana diatur dalam Pasal 13 UUPK yang menyatakan bahwa pelaku usaha dilarang menawarkan, mempromosikan atau mengiklankan obat, obat tradisional, suplemen makanan, alat kesehatan dan jasa pelayanan kesehatan dengan cara menjanjikan pemberian hadiah berupa barang dan/atau jasa lain, dimaksudkan agar konsumen tidak tertarik pada hadiah, tanpa memperhatikan kesesuaian barang yang ditawarkan dengan kondisi kesehatan konsumen yang dipulihkan.

Dari hasil penelitian, konsumen sebagai sasaran dari sebuah iklan ternyata sebagian besar belum mengatahui bahwa ada aturan yang mengatur tentang hak mereka sebagai konsumen dan bagaimana seharusnya iklan yang layak untuk diedarkan. Hal ini yang menjadi salah satu faktor mengapa hingga saat ini masih ada iklan pengobatan tradisional yang melanggar aturan. Menurut data dari Badan Penyelesaian Sengketa Konsumen di Makassar, hingga tahun 2015 belum ada laporan mengenai tuntutan terhadap iklan pengobatan tradisonal yang dianggap merugikan, sedangkan dalam hasil wawancara dari beberapa konsumen pengguna jasa pengobatan tradisional terdapat $40 \%$ konsumen yang merasa tidak puas dan merasa dirugikan oleh iklan pengobatan tradisonal. Pada umumnya mereka merasa dirugikan oleh janji-janji kesembuhan yang diberikan dalam iklan tetapi kenyataannya tidak demikian, sehingga konsumen telah dirugikan secara materi dan waktu.

Dari hasil penelitian, ditemukan bahwa ketidakefektifan aturan yang berlaku dikarenakan sosialisasi yang dilakukan oleh pihak yang berwenang terlambat dilakukan serta belum dilakukan secara menyeluruh kepada pihak - pihak terkait dengan iklan pengobatan tradisional. Sosialisasi hanya dilakukan pada stasiun televisi dan pengobat tradisional saja. Sedangkan pihak media cetak seperti koran luput dari sosialisasi sehingga dalam prakteknya, masih ada iklan pengobatan tradisional yang dicetak ternyata masih melanggar aturan.

Dinas Kesehatan Kota Makassar dalam melakukan pengawasan iklan pengobatan tradisional melakukan kerja sama dengan Komisi Penyiaran Indonesia Daerah yaitu iklan pengobatan tradisional yang ditayangkan di stasiun televisi. Salah satu bentuk pengawasannya yaitu dengan membentuk Tim khusus untuk mengawasi Pengobatan Tradisional. Selain itu, pengawasan juga dilakukan dengan melakukan monitoring iklan setiap hari serta menerima aduan pelanggaran iklan pengobatan tradisional dari pihak manapun yang dibantu oleh Komisi Penyiaran Indonesia Daerah Sulawesi Selatan.

Tanggung jawab tuntutan kerugian akibat dari iklan pengobatan tradisonal sepenuhnya menjadi tanggung jawab pelaku usaha dalam hal ini pihak pengobat tradisional yang diatur dalam Pasal 62 UUPK yaitu sanksi pidana penjara paling lama 5 


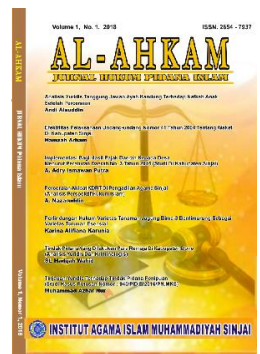

Al-Ahkam

Jurnall Hukum Pidana Islam

Volume 2, No. 2, 2020

ISSN (print) : 2654-7937

ISSN (online) : 2715-0313

Homepage :http://journal.iaimsinjai.ac.id/index.php/al-ahkam/index

tahun atau pidana denda paling banyak Rp.2.000.000.000,- (dua milyar rupiah), adapun jika pelanggaran mengakibatkan luka berat, sakit sekarat, cacat tetap, atau kematian diberlakukan hukum pidana. Adapun sanksi tambahan dalam Pasal 63 menyebutkan terhadap sanksi pidana dalam Pasal 62 dapat dijatuhkan hukuman tambahan berupa;(a) perampasan barang tertentu;(b) pengumuman keputusan hakim(c) pembayaran ganti rugi;(d) perintah penghentian kegiatan tertentu yang menyebabkan timbulnya kerugian konsumen;(e) kewajiban penarikan barang dari peredaran;atau (f) pencabutan izin usaha. Sedangkan sanksi administratif diatur dalam Peraturan Menteri dan Keputusan Menteri Kesehatan berupa pencabutan izin, hingga penutupan tempat pengobatan tradisional. Namun, sanksi administrasi yang selama ini diterapkan dinilai tidak memberikan efek jera, karena masih ada Pengobat tradisional yang melakukan pelanggaran dalam pembuatan iklan.

\section{Simpulan}

Iklan pengobatan tradisonal yang beredar luas dimasyarakat masih memiliki beberapa pelanggaran, walaupun sudah jelas diatur dalam Peraturan Menteri Kesehatan tentang Iklan dan Publikasi Layanan Kesehatan dan Keputusan Menteri Kesehatan tentang Penyelenggaraan Pengobatan Tradisional serta Undang-Undang Nomor 8 Tahun 1999 tentang Perlindungan Konsumen. Ketidakefektivan aturan tersebut disebabkan sosialisasi yang dilakukan terlambat serta dilakukan tidak secara menyeluruh kepada pihak-pihak yang terkait. Adapun bentuk pengawasan yang dilakukan oleh Dinas Kesehatan Kota Makassar yaitu membentuk tim khusus untuk melakukan pengawasan lebih ketat terhadap pengobatan tradisional. Pemberian sanksi administratif dinilai tidak memberikan efek jera. Dinas Kesehatan Kota Makassar bekerja sama dengan Komisi Penyiaran Indonesia Daerah untuk melakukan pengawasan terhadap iklan pengobatan tradisional yang ada dimedia televisi.

\section{Daftar Pustaka}

Amiruddin. (2004). Pengantar Metode Penelitian Hukum. Jakarta: Raja Grafindo Persada. Harianto D. (2010). Perlindungan Hukum Bagi Konsumen Terhadap Iklan yang Menyesatkan. Bogor: Ghalia Indonesia.

Marzuki \& Peter M. (2011). Penelitian Hukum. Surabaya: Kencana.

Miru A. \& Yodo S. (2008). Hukum Perlindungan Konsumen. Jakarta: Raja Grafindo Persada.

Myres K. (2012). Membongkar Sensasi dan Godaan Iklan. Yogyakarta: Jalasutra

Notoatmodjo S. (2010). Etika dan Hukum Kesehatan. Jakarta: Rineka Cipta.

Peraturan Menteri Kesehatan Nomor 1787 Tahun 2010 tentang .Iklan dan Publikasi Layanan Kesehatan.

Simatupang T. (2004). Aspek Hukum Periklanan dalam Perspektif Perlindungan Konsumen. Bandung: Citra Aditya Bakti.

Undang-Undang No.8 Tahun 1999 Tentang Perlindungan Konsumen

Wijaya G. \& Yani A. (2008). Hukum Tentang Perlindungan Konsumen. Jakarta: Gramedia Pustaka Utama. 